\title{
Susceptibility Vessel Sign in the ASTER Trial: Higher Recanalization Rate and More Favourable Clinical Outcome after First Line Stent Retriever Compared to Contact Aspiration
}

Romain Bourcier, ${ }^{\mathrm{a}}$ Mickael Mazighi, ${ }^{\mathrm{b}}$ Julien Labreuche, ${ }^{\mathrm{c}}$ Robert Fahed, ${ }^{\mathrm{b}}$ Raphael Blanc, ${ }^{\mathrm{b}}$ Benjamin Gory, Alain Duhamel, ${ }^{\mathrm{c}}$ Gaultier Marnat, ${ }^{\mathrm{e}}$ Suzana Saleme, ${ }^{\mathrm{f}}$ Vincent Costalat, ${ }^{\mathrm{g}}$ Serge Bracard, ${ }^{\mathrm{d}}$ Hubert Desal, ${ }^{\mathrm{a}}$ Arturo Consoli, ${ }^{\mathrm{h}}$ Michel Piotin, ${ }^{\mathrm{b}}$ Bertrand Lapergue, ${ }^{\mathrm{h}}$ on behalf of the ASTER Trial Investigators

${ }^{a}$ Department of Diagnostic and Interventional Neuroradiology, Guillaume et René Laennec University Hospital, Nantes, France

bepartment of Diagnostic and Interventional Neuroradiology, Rothschild Foundation, Paris, France

'Department of Biostatistics, University Lille, CHRU Lille, Lille, France

${ }^{d}$ Department of Diagnostic and Interventional Neuroradiology, University Hospital of Nancy, Nancy, France

'Department of Diagnostic and Interventional Neuroradiology, University Hospital of Bordeaux, Bordeaux, France

fDepartment of Diagnostic and Interventional Neuroradiology, University Hospital of Limoges, Limoges, France

${ }^{9}$ Department of Diagnostic and Interventional Neuroradiology, University Hospital of Montpellier, Montpellier, France

${ }^{h}$ Department of Stroke Center and Diagnostic and Interventional Neuroradiology, University of Versailles and Saint Quentin en Yvelines,

Foch Hospital, Suresnes, France

Journal of Stroke 2018;20(2):268-276

https://doi.org/10.5853/jos.2018.00192

On page 271, in Table 1, the value '1115 (65-151)' of subgroup 'Imaging to groin puncture' and column heading 'SVS (-)' was input incorrectly. The correct value is '115 (65-151).'

We apologize for any inconvenience that this may have caused. 